\title{
Effect of Metal Thickness on the Sensitivity of Crack-Based Sensors
}

\author{
Eunhan Lee ${ }^{1}$, Taewi Kim ${ }^{1}$, Heeseong Suh ${ }^{1}$, Minho Kim ${ }^{1}$, Peter V. Pikhitsa ${ }^{2}$, \\ Seungyong Han $1, *$ (i), Je-sung Koh ${ }^{1, * \text { (i) }}$ and Daeshik Kang $1, *$ (i) \\ 1 Department of Mechanical Engineering, Ajou University, San 5, Woncheon-dong, Yeongtong-gu, \\ Suwon 443-749, Korea; guyehl@ajou.ac.kr (E.L.); rlaxodnl@ajou.ac.kr (T.K.); gmltjd507@ajou.ac.kr (H.S.); \\ hgh7706@ajou.ac.kr (M.K.) \\ 2 Global Frontier Center for Multiscale Energy Systems, Department of Mechanical and Aerospace \\ Engineering, Seoul National University, Seoul 151-742, Korea; peter@snu.ac.kr \\ * Correspondence: sy84han@ajou.ac.kr (S.H.); jskoh@ajou.ac.kr (J.K.); dskang@ajou.ac.kr (D.K.); \\ Tel.: +82-31-219-2685 (S.H.); +82-31-219-2353 (J.K.); +82-31-219-2345 (D.K.)
}

Received: 30 June 2018; Accepted: 28 August 2018; Published: 31 August 2018

\begin{abstract}
Among many attempts to make a decent human motion detector in various engineering fields, a mechanical crack-based sensor that deliberately generates and uses nano-scale cracks on a metal deposited thin film is gaining attention for its high sensitivity. While the metal layer of the sensor must be responsible for its high performance, its effects have not received much academic interest. In this paper, we studied the relationship between the thickness of the metal layer and the characteristics of the sensor by depositing a few nanometers of chromium $(\mathrm{Cr})$ and gold ( $\mathrm{Au}$ ) on the PET film. We found that the sensitivity of the crack sensor improves/increases under the following conditions: (1) when $\mathrm{Au}$ is thin and $\mathrm{Cr}$ is thick; and (2) when the ratio of $\mathrm{Au}$ is lower than that of $\mathrm{Cr}$, which also increases the transmittance of the sensor, along with its sensitivity. As we only need a small amount of Au to achieve high sensitivity of the sensor, we have suggested more efficient and economical fabrication methods. With this crack-based sensor, we were able to successfully detect finger motions and to distinguish various signs of American Sign Language (ASL).
\end{abstract}

Keywords: metal thickness; sensitivity; crack density; crack-based sensory system; motion detecting system; flexible sensing system

\section{Introduction}

In the last few years, many studies on detecting motions using kinematic, multiple accelerations, miniature inertial, magnetic sensors have been reported in various fields [1-9]. As these sensors have a limitation in terms of wearability and accuracy, a variety of studies have reported flexible, stretchable and high-sensitivity strain or pressure sensors fabricated by graphene [10-12], CNT [13-15], and nanowire composite structures [16-18]. Among these, Kang et al. [19] have provided an ultrahigh-sensitivity (determined as a gauge factor, $\left.\mathrm{GF}=\Delta R / R_{0}\right) / \epsilon$ ) of about 2000, defined through the normalized resistance $\left(R / R_{0}\right)$ variation with the strain $(\epsilon)$, multifunctional nanoscale crack-based sensor inspired by a spider's sensory system. By using this sensor, the pressure of a ladybird, pulse, human speech, and flow rate as a function of time were successfully measured. Since this paper was published, many subsequent studies on topics such as enhancing performance, durability, and transparency, while considering diverse materials, have been carried out [20-27]. Most of the crack sensors studied were fabricated by depositing metals on a polymer substrate. These deposited metals, then, may change the features of these sensors, which makes predicting their characteristics challenging. 
In this paper, we study the relationship between the performance and transmittance of the crack-based sensor and its metal thickness. We present the best combination of metal thickness, namely of chromium $(\mathrm{Cr})$ and gold $(\mathrm{Au})$, with respect to the sensitivity and transmittance of the sensor, and the economy and efficiency of the fabrication process. Using the highly sensitive sensor, we made a motion sensing system which can sense and distinguish signs of American Sign Language (ASL). With reference to the results of this study, it is expected that a sensor that fulfils various human needs can be economically and efficiently made. Also, it can be helpful to understand the relationship between the thickness of metal and the performance of sensor.

\section{Materials and Methods}

\subsection{The Fabrication of a Crack Sensor}

A crack-based sensor is composed of three layers. Two metal layers are deposited by a thermal evaporating system (Thermal Evaporation System, DD high tech Co., Gimpo-si, Gyeonggi-do, Korea) on a $6 \mu \mathrm{m}$ PET film (3026 Mylar thin film, Chemplex, Palm City, FL, USA) substrate. Right before the deposition process, plasma treatment is performed in the oxygen plasma system (CUTE, Femto science Co., Hwaseong-Si, Gyeonggi-do, Korea) at $100 \mathrm{~W}$ for $10 \mathrm{~min}, 0.5$ torr pressure, and $30 \mathrm{sccm}$ flow rate. A $5 \times 40 \mathrm{~mm}$ stainless steel shadow mask is used for constant width and length. Cracks on the metal layers are generated by $2 \%$ strain by using a material testing machine (3342 UTM, Instron Co., Norwood, MA, USA).

\subsection{Resistance Variation Measurement of the Crack Sensor}

To measure the sensitivity of the crack-based sensor, tensile testing is processed by using a material testing machine (3342 UTM, Instron Co., Norwood, MA, USA). The sensor is clamped at each end by the grips of the material testing machine, which leaves the intact part of the sensor to be $30 \mathrm{~mm}$ in length. The sensor is strained at 500 cycles on $2 \%$ strain at $2 \mathrm{~mm} / \mathrm{min}$, and its resistance variation measured by using a Labview-based data acquisition system (PXI-4071, National Instruments Inc., Austin, TX, USA).

\section{Results}

\subsection{The Crack-Based Sensor}

Figure 1a is the schematic illustration of the crack-based sensor. Two metal layers of $\mathrm{Cr}$ and $\mathrm{Au}$ are deposited on a PET substrate by a thermal deposition system. $\mathrm{Cr}$ is deposited on the PET substrate for crack inducement, and $\mathrm{Au}$ is deposited on the $\mathrm{Cr}$ layer as an electron conductor. Figure $1 \mathrm{~b}$ is a cross-sectional scanning electron microscope (SEM) image of the crack-based sensor. A crack that is generated on the metal layers cannot penetrate into the PET substrate in Figure 1b. It can be said, then, that the depth of the crack is same as the thickness of the metal layers. Figure $1 \mathrm{c}, \mathrm{d}$ shows schematic illustrations of the crack sensory systems for which the depth of the metal layers is different. In Figure 1c, the number of cracks is larger and their depth is shallower than those in Figure 1d. As you can see in Figure 1c,d, the depth of the cracks becomes deeper but their density is lowered when the thickness of the metal layers is thicker. 
(a)

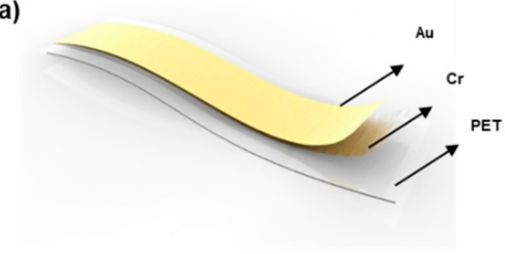

(b)
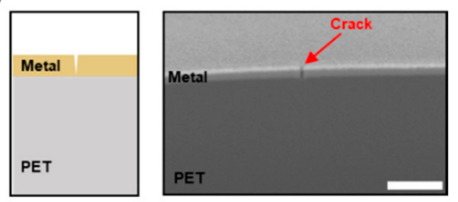

(c)

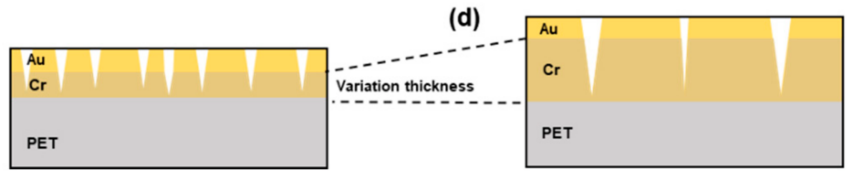

Figure 1. Schematic illustrations and a focused ion beam (FIB) image of the crack sensor. (a) Illustration of the crack sensor; (b) Cross-sectional FIB image of the crack sensor; Scale bar $=500 \mathrm{~nm}$. (c) Illustration of a thin metal layer crack sensor; (d) Illustration of a thick metal layer crack sensor.

\subsection{Resistance Variation of the Crack-Based Sensor and Its Characteristics}

Figure 2a presents plots that show the performance of the sensor and base resistance variation versus the thickness of $\mathrm{Au}$ from 10 to $70 \mathrm{~nm}$ when the $\mathrm{Cr}$ thickness is constant at $50 \mathrm{~nm}$. The orange columns are the GF of the crack sensor, and the red squares are its base resistance. When the crack sensor is stretched by an external strain force, the gaps between the nanoscale cracks are changed, leading to a variation in resistance occurring. When the crack gap opens due to external stress, the performance of the sensor improves, in cases where the degree of the maximum resistance is higher than that of the base resistance. In Figure 2a, GF and base resistance are decreased when the Au is thicker. The performance of the sensor decreases, since the reduced degree of maximum resistance is bigger than that of the base resistance. This is due to the crack density effect. The sensitivity of the crack sensor is dominated by the depth and density of the crack [26]. The resistance change of crack sensor occurs due to the variation of the gap between cracks. When the depth or density of the crack becomes deeper, the intervals between cracks change more dramatically when the same amount of strain is applied. Figure $2 b$ is a plot showing that the density of the crack sensor varies according to $\mathrm{Au}$ thickness when $\mathrm{Cr}$ thickness is constant at $50 \mathrm{~nm}$. When the $\mathrm{Au}$ is thicker, the density of the crack sensor decreases. The result of Figure 2b, the reduction of crack density, causes the result of Figure 2a, the decrease of the sensor GF. Thick $\mathrm{Cr}$ might have inherent film-stress after deposition, and it can affect the low GF. However, as can be seen in Figure S1, when the inherent film-stress is removed by thermal annealing process, there is no big difference in GF value. Hence, the influence of inherent film-stress can be ignored in this experiment.

Figure $2 \mathrm{c}$ is a plot showing the performance of the crack sensor and the base resistance versus the $\mathrm{Cr}$ thickness from 30 to $80 \mathrm{~nm}$ when the Au thickness is constant at $20 \mathrm{~nm}$. As shown in Figure 2a, the red columns show the GF value of the crack sensor and the blue squares the base resistance value of the crack sensor. In Figure 2c, the GF value of the crack sensor increases until the $\mathrm{Cr}$ thickness reaches $60 \mathrm{~nm}$, due to the crack gap opening effect. The greater depth of the cracks causes the crack gap to open wider, resulting in a more dramatic change of the resistance value. When the thickness of $\mathrm{Cr}$ becomes greater than $60 \mathrm{~nm}$, the GF value decreases due to the crack density effect. When the thickness of $\mathrm{Cr}$ deposited on the PET substrate becomes thicker, the density of the cracks in the metal layer decreases [28-31]. H. Jin et al. studied the change of the crack density according to the depth of $\mathrm{Cr}$ deposited on the PET substrate. They reported that the 15-nm-thick film had denser cracks than those that were 70 and $140 \mathrm{~nm}$ thick did. The crack spacings were 2.6, 6.6 and $9.7 \mu \mathrm{m}$ for the 15-, 70and 140-nm-thick films, respectively [30]. As can be seen in Figure 2d, the density of the cracks can be seen to vary with the GF value of the crack sensor. If the thickness of the $\mathrm{Cr}$ is greater than $70 \mathrm{~nm}$, then, in a case where the tensile is applied to the sensor at $2 \%$, the density of the crack is less influential than 
the crack opening effect and consequently, the performance of the sensor is decreased. The value of the base resistance also increases until the $\mathrm{Cr}$ thickness reaches $60 \mathrm{~nm}$, but decreases when it is thicker than $60 \mathrm{~nm}$.
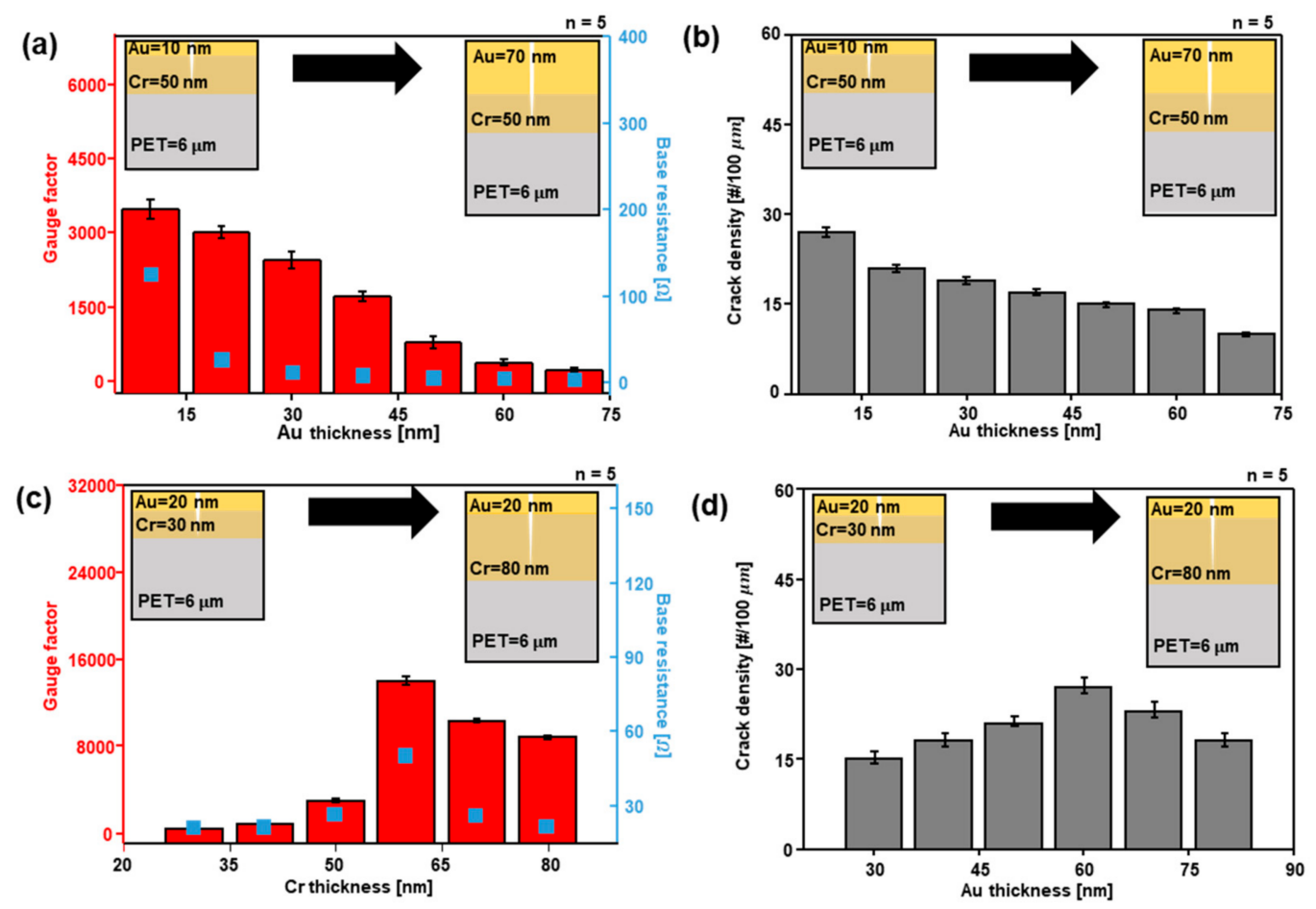

Figure 2. The characteristic variations of the crack sensor according to metal thickness. (a) Gauge factor (red column), base resistance (blue squares) changes of the crack sensor according to Au thickness when the $\mathrm{Cr}$ thickness is constant at $50 \mathrm{~nm}$; (b) Crack density according to Au thickness when the $\mathrm{Cr}$ thickness is constant at $50 \mathrm{~nm}$; (c) Gauge factor (red column), base resistance (blue squares) changes of the crack sensor according to Cr thickness when the Au thickness is constant at $20 \mathrm{~nm}$; (d) Crack density according to $\mathrm{Cr}$ thickness when the Au thickness is constant at $20 \mathrm{~nm}$.

\subsection{Performance Variation and Transmittance of the Crack-Based Sensor}

In the results of Figure 2, we found that the thickness of the metal layer has a great influence on the sensitivity of the sensor. We performed some experiments to find out the relation between sensitivity and metal layer ratio of the crack sensor. Figure $3 a$ is the plot showing the variation of the GF value and the change of the crack density according to the three cases of the ratio of $\mathrm{Cr}$ and $\mathrm{Au}$ thickness when the metal layer of the crack sensor is constant at $60 \mathrm{~nm}$. The leftmost case is when the thicknesses of $\mathrm{Cr}$ and Au are, respectively, $50 \mathrm{~nm}$ and $10 \mathrm{~nm}$; the middle case, $40 \mathrm{~nm}$ and $20 \mathrm{~nm}$; and the rightmost case, $30 \mathrm{~nm}$ for both. The red bars in Figure 3a are the GF of the crack sensor and the blue squares the base resistance of the sensing system. The photos in Figure 3a are the optical images that represent the variation of the crack density. As can be seen in Figure 3a, the GF and the crack density decrease when the ratio of $\mathrm{Au}$ is increased. This is due to the width of the crack and its density. The depth of the crack is constant at $60 \mathrm{~nm}$ since the thickness of the metal layers is constant. When the ratio of $\mathrm{Cr}$ is higher, a large resistance change occurs due to the role of the $\mathrm{Cr}$ layer, which is to resist. Conversely, when the ratio of $\mathrm{Au}$ is higher than that of $\mathrm{Cr}$, the value of GF is low, as can be seen in Figure 3a due to the role of the Au layer as an electrode. $\mathrm{Cr}$ is a more brittle metal than Au. As a result, the density of crack increases when the ratio of $\mathrm{Cr}$ is higher than that of $\mathrm{Au}$. As is shown in Figure 3a, the density of cracks should affect to resistance variance by applied strain. Theoretical analysis of the resistance variation according to strain is in supplementary information. 
(a)

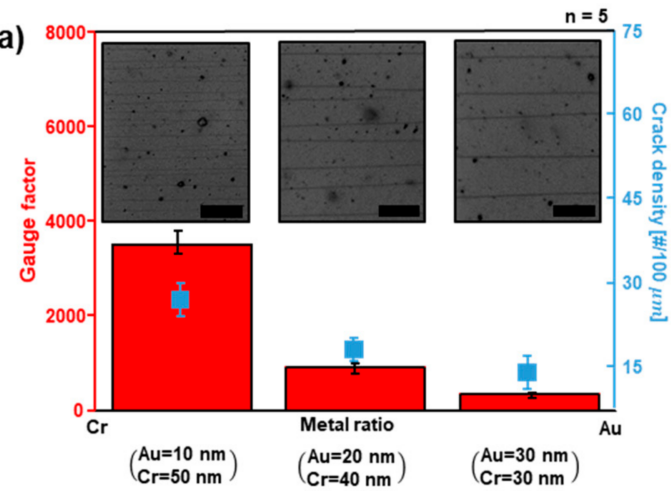

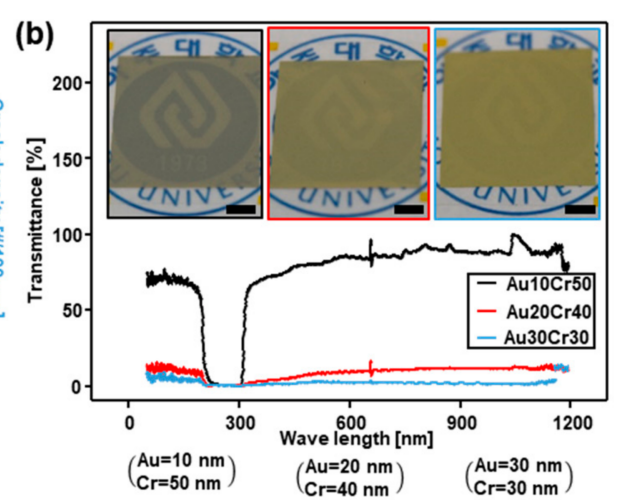

Figure 3. Sensitivity, density and transmittance change of crack sensor according to the ratio of the metal layer. (a) Microscopic images and a plot, gauge factor (red column), crack density (blue square) changes according to the metal ratio. Scale bar $=50 \mu \mathrm{m}$. (b) Transmittance change of crack sensor according to the wave length. Scale bar $=1 \mathrm{~cm}$. (left: Cr50, Au10 Middle: Cr40, Au20, Right: Cr30 Au30).

Transparent devices have strong adaptability in various fields such as display panels [32-34]. The crack sensor presented in this paper is expected to be used for display panels due to its flexible and sensitive characteristics. Figure $3 b$ is a plot representing the value of transmittance of the crack sensor according to the metal ratio in three cases as in Figure 3a. The grey bars are the value of the transmittance, which is highest when the ratio of $\mathrm{Au}$ is low. The photos in Figure $3 \mathrm{~b}$ are the optical images that represent the difference in crack sensor transmittance, showing the same tendency as in Figure 3a.

\subsection{Motion Detecting System}

Detecting finger motion was conducted based on other technologies, such as wavelet transform of surface EMG signal, integrated with triboelectric nanogenerator and filtering image frame [35-37]. We designed a finger motion detecting system using our crack-based sensor. Figure $4 \mathrm{a}$ is an image representing a wearable finger motion detecting system. Five crack sensors are attached to each finger of a nitrile examination glove. Using this system, we detected the finger motion and demonstrated the motion in a simulation. Each sensor located in the five fingers, which were connected via a multi-channel data acquisition system, detected the resistance variation. When bending stress was applied to the crack-based sensor, it worked well without being damaged until the angle of the arc was $40^{\circ}$ and the radius of curvature $\rho$ was $20 \mathrm{~mm}$ (Figure S2). The images in Figure $4 \mathrm{~b}$ are four ASL signs, $\mathrm{A}, \mathrm{J}, \mathrm{O}$, and $\mathrm{U}$. Each sensor mounted on five fingers was connected with a microcontroller (Arduino UNO, Ivrea, Italy). The data detected by sensors were transferred to a simulation program (Blender v.2.79), and a virtual hand in the program moves simultaneously with the gloved human hand. As can be seen in the illustrations of Figure $4 \mathrm{~b}$, the virtual hand in the Blender can demonstrate the finger motion. Figure $4 \mathrm{c}$ shows the plots that present the signals of each finger. The $\mathrm{x}$-axis represents time and the $y$-axis represents the relative change in resistance from sensors attached to five fingers. The red line is the signal that senses the change of the little finger, the blue line the signal from the ring finger, the green line the middle finger, the yellow line the index finger and the pink line the thumb. The value of resistance changes according to the degree of finger bending. As can be seen in Figure $4 a-c$, by using the wearable finger motion detecting system, we were able to distinguish and demonstrate some of the ASL signs. Figure $4 \mathrm{~d}$ is an image showing the pulse sensing system, and Figure $4 \mathrm{e}$ is a plot showing the pulse signal according to time. 

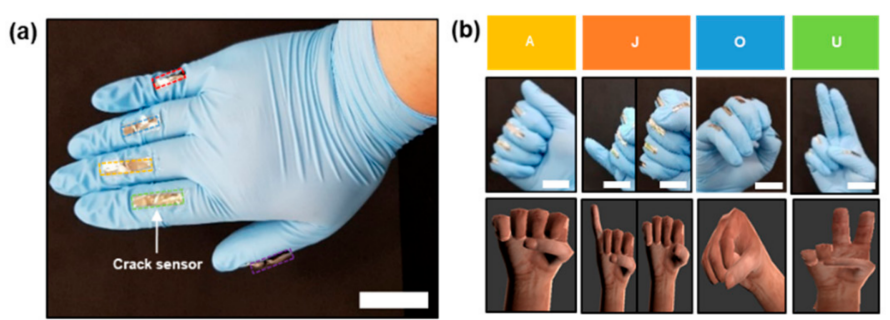

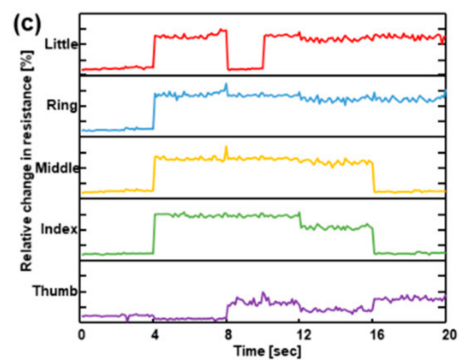

(d)

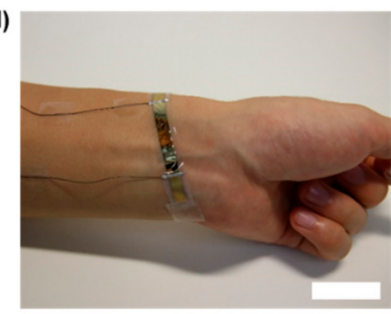

(e) 1

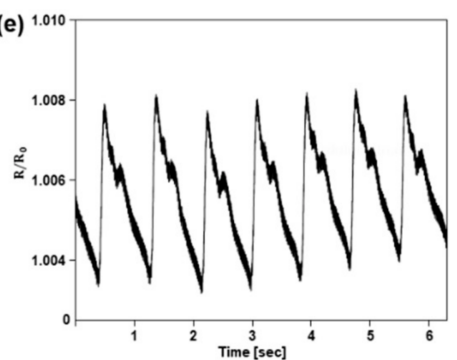

Figure 4. Detecting finger motions and pulse by using the wearable motion detecting system. (a) An image of wearable motion detecting system; (b) Images and illustrations of four ASL signs. (A, J, O, U); (c) Plots representing signals from each finger. (red: little, blue: ring, green: middle, yellow: ring, pink: thumb) Scale bar $=3 \mathrm{~cm}$; (d) Images of pulse signal sensing system. Scale bar $=3 \mathrm{~cm}$; (e) A plot representing the pulse signal according to time.

\section{Discussion}

In this paper, we have reported the variation of the crack sensor sensitivity and transmittance according to its metal thickness. We made the crack sensor by depositing a few nanometers of $\mathrm{Cr}$ and $\mathrm{Au}$ on $6 \mu \mathrm{m}$ PET film and conducting 500 cycles of tensile testing from 0 to $2 \%$. When the $\mathrm{Au}$ is thin or the $\mathrm{Cr}$ is thick, the performance of the crack sensor was noticeable. However, when the Au is thinner than $10 \mathrm{~nm}$, the layer is not able to perform its role as the electrode. Similarly, when the $\mathrm{Cr}$ is thicker than $60 \mathrm{~nm}$, its sensitivity becomes lower due to the decrease in the crack density. When the ratio of $\mathrm{Au}$ is low, the sensitivity and transmittance of the crack sensor increase. With this sensor, we can detect human finger motions, and distinguish ASL signs.

Supplementary Materials: The following are available online at http:/ /www.mdpi.com/1424-8220/18/9/2872/ s1, Figure S1: The variation of GF and Base resistance according to annealing process. Red column indicates GF and blue square means the base resistance. The metal thickness of sensor is Cr $50 \mathrm{~nm}, \mathrm{Au} 20 \mathrm{~nm}$. Figure S2: The schematic illustration of crack-based sensor. $l=15 \mathrm{~mm}, w=5 \mathrm{~mm}, h=6 \mu \mathrm{m}$.

Author Contributions: D.K., S.H. and J.K. conceived and designed the experiments; E.L., H.S. and M.K. performed the experiments; E.L., T.K. and P.V.P. analyzed the data; E.L., D.K., S.H. and J.K. wrote the paper.

Funding: This material is based upon work supported by the Ministry of Trade, Industry \& Energy (MOTIE, Korea) under Industrial Technology Innovation Program. No. 20000512, “Development of Task Planning, Gripping and Manipulation Technologies of Deformable Objects based on Machine Learning for Manufacturing and Logistical Process". Daeshik Kang, Seungyong Han, and Je-sung Koh acknowledge financial support by the new faculty research fund of Ajou University and the Ajou University research fund. Daeshik Kang acknowledges financial support by Basic Science Research Program through the National Research Foundation of Korea (NRF) funded by the Ministry of Science, ICT \& Future Planning (2016R1C1B1009689).

Acknowledgments: D.K. thanks Mansoo Choi of Seoul National University for his advice and support.

Conflicts of Interest: The authors declare no conflict of interest.

\section{References}

1. Lee, H.; Glasper, M.J.; Li, X.; Nychka, J.A.; Batcheller, J.; Chung, H.-J.; Chen, Y. Preparation of fabric strain sensor based on graphene for human motion monitoring. J. Mater. Sci. 2018, 53, 9026-9033. [CrossRef] 
2. Xu, H.; Lu, Y.F.; Xiang, J.X.; Zhang, M.K.; Zhao, Y.J.; Xie, Z.Y.; Gu, Z.Z. A multifunctional wearable sensor based on a graphene/inverse opal cellulose film for simultaneous, in situ monitoring of human motion and sweat. Nanoscale 2018, 10, 2090-2098. [CrossRef] [PubMed]

3. Zhang, J.; Cao, Y.; Qiao, M.; Ai, L.; Sun, K.; Mi, Q.; Zang, S.; Zuo, Y.; Yuan, X.; Wang, Q. Human motion monitoring in sports using wearable graphene-coated fiber sensors. Sens. Actuators A Phys. 2018, 274, 132-140. [CrossRef]

4. Saha, C.; O'donnell, T.; Wang, N.; McCloskey, P. Electromagnetic generator for harvesting energy from human motion. Sens. Actuators A Phys. 2008, 147, 248-253. [CrossRef]

5. Yang, A.Y.; Jafari, R.; Sastry, S.S.; Bajcsy, R. Distributed recognition of human actions using wearable motion sensor networks. J. Ambient Intell. Smart Environ. 2009, 1, 103-115.

6. Zhu, R.; Zhou, Z. A real-time articulated human motion tracking using tri-axis inertial/magnetic sensors package. IEEE Trans. Neural Syst. Rehabil. Eng. 2004, 12, 295-302. [CrossRef] [PubMed]

7. Roetenberg, D.; Luinge, H.; Slycke, P. Xsens MVN: Full 6DOF Human Motion Tracking Using Miniature Inertial Sensors; Technical Report; Xsens Motion Technologies BV: Enschede, The Netherlands, 2009; Volume 1.

8. Mantyjarvi, J.; Himberg, J.; Seppanen, T. Recognizing human motion with multiple acceleration sensors. In Proceedings of the 2001 IEEE International Conference on Systems, Man, and Cybernetics, Tucson, AZ, USA, 7-10 October 2001; pp. 747-752.

9. Najafi, B.; Aminian, K.; Paraschiv-Ionescu, A.; Loew, F.; Bula, C.J.; Robert, P. Ambulatory system for human motion analysis using a kinematic sensor: Monitoring of daily physical activity in the elderly. IEEE Trans. Biomed. Eng. 2003, 50, 711-723. [CrossRef] [PubMed]

10. Park, J.J.; Hyun, W.J.; Mun, S.C.; Park, Y.T.; Park, O.O. Highly stretchable and wearable graphene strain sensors with controllable sensitivity for human motion monitoring. ACS Appl. Mater. Interfaces 2015, 7, 6317-6324. [CrossRef] [PubMed]

11. Wang, Y.; Wang, L.; Yang, T.; Li, X.; Zang, X.; Zhu, M.; Wang, K.; Wu, D.; Zhu, H. Wearable and highly sensitive graphene strain sensors for human motion monitoring. Adv. Funct. Mater. 2014, 24, 4666-4670. [CrossRef]

12. Wang, Y.; Yang, T.; Lao, J.; Zhang, R.; Zhang, Y.; Zhu, M.; Li, X.; Zang, X.; Wang, K.; Yu, W.; et al. Ultra-sensitive graphene strain sensor for sound signal acquisition and recognition. Nano Res. 2015, 8 , 1627-1636. [CrossRef]

13. Cai, L.; Song, L.; Luan, P.; Zhang, Q.; Zhang, N.; Gao, Q.; Zhao, D.; Zhang, X.; Tu, M.; Yang, F.; et al. Super-stretchable, transparent carbon nanotube-based capacitive strain sensors for human motion detection. Sci. Rep. 2013, 3, 3048. [CrossRef] [PubMed]

14. Kang, I.; Schulz, M.J.; Kim, J.H.; Shanov, V.; Shi, D. A carbon nanotube strain sensor for structural health monitoring. Smart Mater. Struct. 2006, 15, 737. [CrossRef]

15. Yamada, T.; Hayamizu, Y.; Yamamoto, Y.; Yomogida, Y.; Izadi-Najafabadi, A.; Futaba, D.N.; Hata, K. A stretchable carbon nanotube strain sensor for human-motion detection. Nat. Nanotechnol. 2011, 6, $296-301$. [CrossRef] [PubMed]

16. Amjadi, M.; Pichitpajongkit, A.; Lee, S.; Ryu, S.; Park, I. Highly stretchable and sensitive strain sensor based on silver nanowire-elastomer nanocomposite. ACS Nano 2014, 8, 5154-5163. [CrossRef] [PubMed]

17. Gong, S.; Schwalb, W.; Wang, Y.; Chen, Y.; Tang, Y.; Si, J.; Shirinzadeh, B.; Cheng, W. A wearable and highly sensitive pressure sensor with ultrathin gold nanowires. Nat. Commun. 2014, 5, 3132. [CrossRef] [PubMed]

18. Kim, K.K.; Hong, S.; Cho, H.M.; Lee, J.; Suh, Y.D.; Ham, J.; Ko, S.H. Highly sensitive and stretchable multidimensional strain sensor with prestrained anisotropic metal nanowire percolation networks. Nano Lett. 2015, 15, 5240-5247. [CrossRef] [PubMed]

19. Kang, D.; Pikhitsa, P.V.; Choi, Y.W.; Lee, C.; Shin, S.S.; Piao, L.; Park, B.; Suh, K.-Y.; Kim, T.; Choi, M. Ultrasensitive mechanical crack-based sensor inspired by the spider sensory system. Nature 2014, 516, 222-226. [CrossRef] [PubMed]

20. Choi, Y.W.; Kang, D.; Pikhitsa, P.V.; Lee, T.; Kim, S.M.; Lee, G.; Tahk, D.; Choi, M. Ultra-sensitive Pressure sensor based on guided straight mechanical cracks. Sci. Rep. 2017, 7, 40116. [CrossRef] [PubMed]

21. Kim, D.-S.; Choi, Y.W.; Lee, T.; Lee, G.; Kang, D.; Choi, M.; Lee, D.-W. Photocurable PUA (Poly Urethaneacrylat) cantilever integrated with ultra-high sensitive crack-based sensor. In Proceedings of the 2017 19th International Conference on Solid-State Sensors, Actuators and Microsystems (TRANSDUCERS), Kaohsiung, Taiwan, 18-22 June 2017; pp. 78-81. 
22. Kim, T.; Lee, T.; Lee, G.; Choi, Y.W.; Kim, S.M.; Kang, D.; Choi, M. Polyimide Encapsulation of Spider-Inspired Crack-Based Sensors for Durability Improvement. Appl. Sci. 2018, 8, 367. [CrossRef]

23. Lee, G.; Lee, T.; Choi, Y.W.; Pikhitsa, P.V.; Park, S.J.; Kim, S.M.; Kang, D.; Choi, M. Metal-elastomer bilayered switches by utilizing the superexponential behavior of crack widening. J. Mater. Chem. C 2017, 5, 10920-10925. [CrossRef]

24. Lee, T.; Choi, Y.W.; Lee, G.; Kim, S.M.; Kang, D.; Choi, M. Crack-based strain sensor with diverse metal films by inserting an inter-layer. RSC Adv. 2017, 7, 34810-34815. [CrossRef]

25. Lee, T.; Choi, Y.W.; Lee, G.; Pikhitsa, P.V.; Kang, D.; Kim, S.M.; Choi, M. Transparent ITO mechanical crack-based pressure and strain sensor. J. Mater. Chem. C 2016, 4, 9947-9953. [CrossRef]

26. Park, B.; Kim, J.; Kang, D.; Jeong, C.; Kim, K.S.; Kim, J.U.; Yoo, P.J.; Kim, T.I. Dramatically Enhanced mechanosensitivity and signal-to-noise ratio of nanoscale crack-based sensors: Effect of crack depth. Adv. Mater. 2016, 28, 8130-8137. [CrossRef] [PubMed]

27. Park, B.; Lee, S.; Choi, H.; Kim, J.U.; Hong, H.; Jeong, C.; Kang, D.; Kim, T.-I. A semi-permanent and durable nanoscale-crack-based sensor by on-demand healing. Nanoscale 2018, 10, 4354-4360. [CrossRef] [PubMed]

28. Andersons, J.; Tarasovs, S.; Leterrier, Y. Analysis of thin film cracking and buckling on compliant substrate by fragmentation test. Key Eng. Mater. 2007, 348-349, 329-332. [CrossRef]

29. Cordill, M.; Taylor, A.; Schalko, J.; Dehm, G. Fracture and delamination of chromium thin films on polymer substrates. Metall. Mater. Trans. A 2010, 41, 870-875. [CrossRef]

30. Jin, H.; Lu, W.-Y.; Cordill, M.; Schmidegg, K. In situ study of cracking and buckling of chromium films on PET substrates. Exp. Mech. 2011, 51, 219-227. [CrossRef]

31. Jobin, V.; Raj, R.; Phoenix, S. Rate effects in metal-ceramic interface sliding from the periodic film cracking technique. Acta Metall. Mater. 1992, 40, 2269-2280. [CrossRef]

32. Blonder, G.E.; Johnson, B.H. Illuminated Transparent Display with Microtextured Back Reflector. EP Patent 5,349,503, 20 September 1994.

33. Charlier, M.L.; Gitzinger, T.E.; Ma, J.J.; Schirtzinger, T.R. Dual Sided Transparent Display Module and Portable Electronic Device Incorporating the Same. WO Patent US 8,493,364 B2, 23 July 2013.

34. Fitch, T.R.; Oberpriller, M.L. Vehicle Computer System with Transparent Display. US Patent 9,235,553 B2, 12 January 2016.

35. Oka, K.; Sato, Y.; Koike, H. Real-time fingertip tracking and gesture recognition. IEEE Comput. Graph. Appl. 2002, 22, 64-71. [CrossRef]

36. Dhakar, L.; Pitchappa, P.; Tay, F.E.H.; Lee, C. An intelligent skin based self-powered finger motion sensor integrated with triboelectric nanogenerator. Nano Energy 2016, 19, 532-540. [CrossRef]

37. Jiang, M.; Wang, R.; Wang, J.; Jin, D. A method of recognizing finger motion using wavelet transform of surface EMG signal. In Proceedings of the 27th Annual International Conference of the Engineering in Medicine and Biology Society, Shanghai, China, 17-18 January 2006; pp. 2672-2674. 